\title{
A TEORIA DO DESENVOLVIMENTO E A PROBLEMÁTICA DA URBANIZAÇÃO NA AMÉRICA LATINA:
}

\author{
UMA PRIMEIRA APROXIMAÇÃO
}

Milena Fernandes Oliveira

\begin{abstract}
R E S U M O : Nos anos 1960 e 70, a teoria do desenvolvimento latino-americana passou por um processo de diversificação e sofisticação que tornou a Economia mais próxima das Ciências Sociais. A produção teórica deixou o tratamento puramente econômico do problema do desenvolvimento econômico, como a deterioraçâo dos termos de intercâmbio, a geração do excedente e o investimento, a fim de avançar para problemáticas que contemplassem um tratamento que desvendasse a totalidade social. Nesse sentido, a interdisciplinaridade dos temas tratados, incluindo o tema clássico da industrialização, passou a ser valorizada. Ao mesmo tempo que a teoria do desenvolvimento torna-se mais próxima de uma economia politica do desenvolvimento, os temas tratados ajudam a consolidar essa sofisticação, mostrando as demais facetas do subdesenvolvimento e da dependência A necessidade de explicar as raizes do subdesenvolvimento levou ao estudo da História e também a uma abordagem das relaçôes sociais como relaçôes de classes. Um olhar crítico sobre o papel do Estado levou a uma ampla utilizaçâo da Ciência Política e das estruturas de poder. Um estudo sobre a cultura de consumo exigiu o aporte da antropologia econômica. Nessa reconstrução da disciplina, novos temas foram contemplados, como a urbanização periférica, a estrutura de consumo, a estrutura agrária e a heterogeneidade regional. Este trabalho pretende entender como o estudo da urbanização à periferia do sistema, dada sua especificidade e complexidade, contribuiu para reforçar esse processo de sofisticação da teoria do desenvolvimento econômico latino-americana, principalmente em seu recurso à História e às demais Ciências Sociais, como a Sociologia e a Ciência Política.
\end{abstract}

P A L A V R A S - C H A V E : desenvolvimento socioeconômico; urbanizaçâo; teoria do desenvolvimento; capitalismo; América Latina.

\section{INTRODUÇÃO}

Este artigo pretende traçar algumas considerações sobre a relação entre a teoria do desenvolvimento econômico e o processo de urbanizaçáo na América Latina nos anos 1960 e 70. Com as transformaçóes aceleradas que consolidaram o capitalismo no continente, vieram novos dilemas que levaram os teóricos do desenvolvimento a sofisticar suas teorias, aproximando-as mais da História e das Ciências Sociais.

Nos anos 1960 e 70, alguns países latino-americanos, como Brasil, Argentina e México, consolidavam os seus capitalismos nacionais, sem, no entanto, romper 
com a condição do subdesenvolvimento. Na voz de Raúl Prebisch, Celso Furtado, Aníbal Pinto, Osvaldo Sunkel e Pedro Paz, o subdesenvolvimento passou, cada vez mais, a ser entendido como um problema de estrutura, cuja superação não está restrita somente ao processo de industrialização, mas à superação de outros entraves estruturais, de natureza social, política e cultural. Nesse sentido, o processo de urbanização acelerada pelo qual passaram esses países desnudou algumas contradiçôes estruturais: a difícil urbanização sem a reforma agrária; a urbanização calcada sobre um crescimento exagerado do setor terciário em relação ao secundário; a absorção de novos padrôes de consumo, calcados em uma ainda maior concentração de renda; a passagem à estrutura concentrada do capitalismo, mantendo-se estruturas clientelistas de poder; a acentuação das desigualdades regionais, sob as quais se compreendia o processo de aceleraçấo da urbanização em regiōes mais desenvolvidas, enquanto da persistência de um setor pouco produtivo, muito próximo ao nível de subsistência, em regiōes subdesenvolvidas. Não raro, os golpes militares aos quais a América assistiu nessas décadas foram resultado e causa da preservação de estruturas tradicionais de poder.

Antes de tratarmos de alguns dos autores que se debruçaram sobre o esforço da relação entre a teoria do desenvolvimento e o processo específico de urbanização latino-americano, há que atentar para a forma como entendemos a relação entre capitalismo e urbanização e como esta relação se apresenta de maneira específica para a América Latina. Este é o ponto a ser desenvolvido no próximo tópico. A seguir, apresentamos um breve panorama da teoria do desenvolvimento na América Latina e como esta sofre uma inflexão nos anos 1960 e 70, no sentido de ampliar o escopo da abordagem estruturalista, introduzindo as contribuiçóes da Sociologia, da Ciência Política e da Antropologia para a Economia. Um último tópico apresenta como, diante do processo de urbanizaçáo latino-americana, esse esforço de complexificação da análise da teoria do desenvolvimento ganha maior solidez. A História é incorporada à análise da teoria estruturalista, o que consiste em um movimento de duplo sentido: tanto a teoria se modifica no sentido de incorporar os dilemas inerentes ao processo de consolidação do capitalismo na América Latina quanto a própria teoria, suficientemente abrangente e complexa, passa a ser um instrumento de intervenção na realidade e de sua modificação.

Como a intenção não é mapear todas as interpretaçôes sobre o processo de urbanização na América Latina, e sim fazer um diálogo entre os dilemas da urbanizaçấo latino-americana e a teoria do desenvolvimento, preferimos distribuir os aportes teóricos segundo alguns temas. Assim, levantamos alguns aspectos comuns aos autores: o retorno à História; a relação dialética entre rural e urbano; a ligação entre urbanização e industrialização, que substituímos pela relação mais complexa entre urbanização e capitalismo, entendendo a urbanização como algo necessário à consolidaçấo deste; a questão das classes no mundo urbano e suas relaçóes com o Estado e com as demais classes, incluindo, dentro desse tema, o debate sobre o direito à cidade.

Alguns autores foram privilegiados no trabalho, tanto pela relevância dos temas tratados para a compreensão da especificidade do desenvolvimento capitalista na América Latina quanto pelo esforço de diálogo com a teoria do desenvolvimento econômico. Alguns dos autores aqui tratados, Aníbal Quijano, Martha Schteingart, Luiz Pereira, Paul Singer e Fernando Henrique Cardoso, analisam, mais estreita- 
mente, a relação entre o capitalismo latino-americano e o processo de urbanização específico; outros autores, como Raúl Prebisch, Celso Furtado e Aníbal Pinto, analisam o processo como um todo, mas náo deixam de considerar o processo de urbanização a partir do momento em que se torna evidente.

A urbanização torna-se, assim, um tema privilegiado e clássico do desenvolvimento latino-americano, mostrando cruamente como as naçóes latino-americanas entram na fase de conclusão de suas industrializaçôes e seus capitalismos sem romperem com sua condição periférica, subdesenvolvida e dependente.

\section{AS TRANSFORMAÇÕES DO CAPITALISMO NA AMÉRICA LATINA NOS ANOS 1960 E 70}

As décadas de 60 e 70, dentro das quais se realizam os milagres econômicos em alguns países da América Latina, como Chile, Argentina, Brasil e México, mostraram que as heterogeneidades estruturais, características das sociedades periféricas, não haviam desaparecido, senão se agudizado. $\mathrm{O}$ processo acelerado de industrializaçáo substitutiva combinado a regimes autoritários contribuiu para a acentuação da desigualdade entre as classes, das disparidades setoriais e da concentração regional de renda.

A intensa urbanização pela qual passam esses países nessas duas décadas é uma prova de como as heterogeneidades estruturais sempre estão a se reproduzir em novas dimensões, à medida que avança também o processo de industrialização com as contradiçôes que lhe são inerentes dentro do capitalismo subdesenvolvido.

Os anos 1960 se abrem, na América Latina, com o esgotamento de uma fase do processo de substituição de importaçôes. Este fora alimentado, durante os anos 1950, pela elevada liquidez do mercado internacional, decorrente da finalização do processo de reconstrução dos países europeus, que privilegiam, na segunda metade dos anos 50, a exportação de capitais e produtos manufaturados aos mercados latino-americanos.

Também é o momento do acirramento dos conflitos entre os blocos capitalista e socialista, principalmente a partir da Revoluçáo Cubana de 1959 e a consequente crise dos mísseis em 1962.

Se, no começo dos anos 1960, as reflexôes sobre o desenvolvimento econômico são inspiradas pelo avanço do bloco socialista, voltando-se para a temática das reformas sociais, particularmente a agrária, por outro lado, o modelo de capitalismo que passou a caracterizar o desenvolvimento latino-americano na segunda metade dos anos 60 foi o modelo excludente. Segundo os teóricos, este teria se assentado na concentração de renda, importante para dar continuidade ao crescimento com base no consumo de bens duráveis, no endividamento externo e na obstrução das vias democráticas de participação política.

Ainda nos anos 1960, enquanto nos Estados Unidos da América (EUA), Europa e Japão os aumentos de produtividade não foram tão elevados, nem foram repassados aos salários, mantendo o nível da demanda efetiva baixo, os "milagres econômicos" que se sucederam na América Latina se caracterizaram por altas taxas de investimento, no setor de bens de produçáo e no setor de bens de consumo duráveis, em relação ao Produto Interno Bruto (PIB) (OLIVEIRA; ROBERTS, 2005). 
Em alguns países latino-americanos avançou-se para a diversificaçáo da pauta exportadora, com a produção de alguns bens manufaturados para o comércio exterior, enquanto em outros manteve-se a especialização na produção de alguns poucos produtos primários, com difusão restrita do progresso tecnológico a este setor. Algumas economias de mercado subdesenvolvidas haviam conseguido articular suas exportaçóes de maneira mais dinâmica a algumas economias desenvolvidas. Isso refletiu o avanço para um novo tipo de geopolítica, no qual os diversos países subdesenvolvidos estabelecem diferentes tipos de relaçōes de dependência com os países centrais, acentuando as disparidades regionais e criando duas Américas Latinas: uma com elevadas taxas de crescimento e produção de bens manufaturados para exportação; e outra com baixíssima taxa de investimento em relação ao PIB (OLIVEIRA; ROBERTS, 2005).

Enquanto a taxa de produtividade caía nas economias centrais, os níveis de crescimento das economias latino-americanas chegaram a ser 4 vezes maior nos anos 1960 e 70, em relação ao que havia sido nessas economias em anos anteriores (OLIVEIRA; ROBERTS, 2005).

Nesse contexto de acentuado crescimento, observa-se a preservação de antigas heterogeneidades estruturais e a criação de novas. $\mathrm{O}$ processo de urbanização, que está atrelado à própria consolidação do capitalismo, é a expressão cabal de como estruturas heterogêneas são preservadas e outras são criadas à medida que se avança na consolidação do capitalismo latino-americano:

[...] as mudanças na estrutura social urbana e, de modo especial, aquelas da estrutura ocupacional, ocorridas na América Latina da década de 30 a de 80 [...] resultaram da conjugação de três processos: a grande urbanização, a industrialização em seus diferentes estágios e a progressiva importância, nas economias latino-americanas, do setor de serviços, tanto dos tradicionais, quanto dos modernos associados à expansão da burocracia do governo e às práticas empresariais do século XX [...]. Nos países desenvolvidos, os processos semelhantes produziram uma convergência das estruturas sociais: a expansão das classes médias, a consolidação de uma classe trabalhadora industrial e a melhoria do bem estar geral da populaçáo. Na América Latina, houve uma maior heterogeneidade dos padróes de estratificação. Sua dependência da tecnologia estrangeira e, em grau crescente, de financiamentos externos, aliada ao papel que a região desempenhava na economia mundial como fornecedora de produtos primários e, portanto, de base rural, resultou numa modernização irregular, tanto entre países, quanto entre regiôes de um mesmo país". (OLIVEIRA; ROBERTS, 2005, p. 299).

O crescimento industrial e a urbanização acelerados viriam acompanhados da acentuação de uma série de desigualdades que se agravariam nas décadas seguintes e que ainda podem ser vistas nas grandes metrópoles. $\mathrm{O}$ crescimento industrial foi feito sob base de tecnologia intensiva em capital, mas, em contraposição, empregos foram gerados no setor de serviços, cujo inchaço seria uma das características das grandes cidades na América Latina. A estratificação social desequilibrou-se a favor das classes médias, que passaram a ser o motor do consumo de bens de consumo duráveis. Os trabalhadores de grandes indústrias, ligadas ao setor de base, tornaram-se como uma elite das classes trabalhadoras, reforçando a diferenciação social dentro da classe operária e ressaltando a dificuldade de organização imposta pelos regimes autori- 
tários. Na grande cidade, o migrante vindo da zona agrária ou da regiáo Nordeste, trabalhador da construção civil, passou a fazer parte da paisagem, não raro como membro das grandes periferias urbanas. O processo de urbanização também era, em si, criador de centros e periferias, urbanos e regionais.

A era que se abre com os milagres econômicos nos países latino-americanos e vai até as suas crises da dívida foi não somente uma era de elevado crescimento como também uma das mais profícuas em termos de produção de interpretaçôes do processo de desenvolvimento capitalista latino-americano. Com as transformaçóes acontecidas entre os anos 1950 e 70, entendeu-se que, a despeito da superação de algumas etapas necessárias ao desenvolvimento econômico, como a industrialização, por exemplo, desigualdades continuavam a existir. Descobriu-se que a produção e reprodução de desigualdades, processo inerente ao capitalismo, acontecia de forma diferente na América Latina, sem, por exemplo, a criação de compensaçóes que pudessem aliviar a intensa exclusão social e a elevada concentração de renda (FERNANDES, 2001). Disso resultaria a frustração com o processo de desenvolvimento e a necessidade de sua compreensáo de um ponto de vista mais amplo, que seria a sociedade como um todo. Daí nasceriam as teorias do desenvolvimento com preocupaçôes não somente voltadas ao crescimento econômico mas ao desenvolvimento social e à superação de entraves estruturais de toda ordem: econômicos, sociais e políticos.

Para além da visão do desenvolvimento latino-americano formulada nos anos 1940 e 50, e segundo a qual o subdesenvolvimento era um produto das relaçóes travadas entre centro e periferia, mas poderia ser superado pela industrializaçáo, procura-se criar uma abordagem estruturalista mais real, informada pela História e pela Economia Política. A heterogeneidade, característica da estrutura subdesenvolvida e periférica, não é simplesmente eliminada pelo processo de industrializaçáo. Ao contrário, este pode reproduzir antigas heterogeneidades e trazer novas, como se observa pelo processo de urbanização latino-americana. As heterogeneidades se reproduzem e se incrustam em diferentes dimensôes da sociedade à medida que o capitalismo avança na América Latina.

\section{A TEORIA DO DESENVOLVIMENTO LATINO-AMERICANA E SUAS INFLEXÕES}

O aparato teórico cepalino, construído a partir da crítica à teoria das vantagens comparativas, nasce, em finais dos anos 1940, para explicar como a estrutura de comércio exterior, que deveria contribuir para o máximo de progresso das naçốes, criou, ao contrário, discrepâncias crescentes entre as diferentes regióes do planeta.

Ao contrário das teorias que nasceram para explicação do subdesenvolvimento no leste europeu, associando o atraso à condição agrícola dos países da regiáo ${ }^{1}$, a teoria do desenvolvimento latino-americana parte da estrutura de comércio exterior, pois as naçôes latino-americanas teriam em comum o seu passado colonial e escravista. Portanto, sua condição de primário-exportadoras, que caracteriza sua estrutura homogênea e especializada, fora precedida de sua condição colonial, dentro da qual se circunscrevera essa especialização inicial.

Prebisch, o primeiro autor a sistematizar os conceitos centrais da teoria cepalina no seu Manifesto Latino-americano, assim intitulado por Hirschman, também relaciona o subdesenvolvimento à condição agrícola e ao excedente de mão de obra ${ }^{2}$. Da
1 Citamos como exemplo de estudos pioneiros na problemática do desenvolvimento europeu os trabalhos de Paul N. Rosenstein-Rodan, Problemas de industrialização da Europa do Leste e do Sudeste (1943); Ragnar Nurkse, Problemas da formação de capitais em países subdesenvolvidos (1951) e Walt W. Rostow, A decolagem para o crescimento auto-sustentado (1956).

2 Enquanto o debate sobre a formação de capital se travaria com Nurkse, o debate sobre o excedente estrutura de mão de obra se travaria com Lewis. 
3 A economia política marxista, análise das contradições entre forças produtivas capitalistas e suas relações de produção, é transformada em teoria do desenvolvimento a partir das análises de Lênin e Trotsky sobre o capitalismo na Rússia. 0 desenvolvimento do capitalismo na Rússia, obra escrita por Lênin em 1905, traz em seu cerne a reflexão de que, relacionado aos diferentes graus e estruturas de atraso, teremos diferentes passagens ao capitalismo. Essa ideia, expressa no conceito de "desenvolvimento desigual e combinado", retomado por Trostky em 1929, aponta para a possibilidade de combinação entre relações de produção arcaicas e forças produtivas modernas e vice-versa. Os diferentes capitalismos assistiriam a diferentes tipos de contradições, dependendo da maneira como se havia combinado o arcaico e o moderno. Ao lado do estudo sobre o desenvolvimento do capitalismo na Rússia, começam-se a elaborar também as teorias sobre a relação entre o imperialismo e o subdesenvolvimento. Embora o estudo de Lênin, $O$ imperialismo, fase superior do capitalismo, só tenha vindo à tona com a revolução de 1917, a reflexão sobre o processo já começa na revolução de 1905, que, para Trotsky, teria sido a decorrência imediata da guerra russo-japonesa, da qual a Rússia saiu perdedora. Para Lênin e Trotsky, esta já seria uma guerra entre potências que adentravam a um novo momento do capitalismo, o capitalismo monopolista ou o imperialismo. mesma forma como Rodan, que escreve em 1943, pregava que o único caminho para o desenvolvimento era a industrialização.

Diferentemente, no entanto, define a estrutura econômica dos países latino-americanos a partir de sua inserção periférica no comércio internacional que, em contraposição aos países centrais, difusores e apropriadores de progresso tecnológico, são exportadores de matérias-primas e importadores de produtos manufaturados.

Esse pequeno retorno à teoria do desenvolvimento dos anos 1940 e 50 é importante para se mostrar como, de uma teoria que nascia do diálogo com a teoria neoclássica e keynesiana, a teoria do desenvolvimento dos anos 1960 e 70 sofistica suas análises a partir da Economia Política, interpretando o subdesenvolvimento como uma estrutura capitalista específica e caracterizada pela heterogeneidade (FURTADO, 2000).

Tal heterogeneidade das economias periféricas, em contraposição aos centros homogêneos, devia-se ao fato de o progresso tecnológico concentrar-se somente no setor exportador, mantendo ao lado deste um setor arcaico imenso (FURTADO, 2000). Este setor arcaico, predominantemente agrícola e com excedente de mão de obra, pressionava tanto a produtividade quanto os salários para baixo, o que permitia que os preços de produtos primários fossem, ao longo do tempo, deteriorando-se em relação aos preços de produtos manufaturados. Isso geraria, por sua vez, um diferencial de rendas médias do setor exportador do centro em relação à periferia, o que explicaria o aumento das disparidades entre os dois polos do sistema.

A sofisticação desse aparato inicial, centrado em uma análise keynesiana aplicada às economias periféricas, dá-se, nos anos 1960 e 70, pela percepção de que a industrializaçâo não poderia, por si só, conduzir um país ao desenvolvimento, tendo em vista que outras esferas da sociedade, como o Estado e a estrutura de classes, contribuíam para alimentar a heterogeneidade estrutural característica da economia subdesenvolvida. Nos anos 1970, aliás, a industrialização não somente deixa de ser condição para o desenvolvimento como a forma como foi feita serviu para aumentar as disparidades, tanto setoriais quanto sociais e regionais. Essa é a ideia contida na concepção de "estilos de desenvolvimento", cara à Comissão Econômica para a América Latina e o Caribe (CEPAL) dos anos 1970, e que vê no processo de industrialização de bens duráveis o aumento do endividamento, das pressóes sobre o balanço de pagamentos e da concentração de renda (PINTO, 2000).

A leitura marxista do processo verá, por trás da estrutura centro-periferia e dos processos de desenvolvimento e subdesenvolvimento, dois tipos de sociedade capitalista diferentes, compostas por arranjos de classes diferentes, sendo também peculiar a relação entre estas e o Estado e entre Estado e capitalismo (FURTADO, 2000). Além disso, pensa-se, cada vez mais, em um processo de transição específico ao capitalismo, que teria conformado a estrutura subdesenvolvida, com contradiçóes entre forças produtivas e relaçôes sociais específicas (OLIVEIRA, 2003).

As décadas de 1960 e 70, nas quais se levantam movimentos sociais em diversos países, presenciam a retomada da teoria marxista nas Ciências Sociais como um todo. Não somente a teoria do desenvolvimento econômico mas também a Geografia, a Sociologia, a Ciência Política e a Antropologia transformam-se à luz da releitura da teoria marxista. ${ }^{3}$

A ideia de dependência nasce de uma releitura da Economia Política e sua relação com a teoria do desenvolvimento. Tanto na abordagem cepalina quanto na abordagem mais propriamente marxista, a ideia de dependência aparece na expli- 
cação de porquê o subdesenvolvimento tende a se reproduzir. Seja por uma imposição externa, criada pelo capitalismo como sistema mundial, seja por uma relação entre interesses externos e internos, o importante é o avanço por que passa a teoria do desenvolvimento quando se propôe uma análise de classes, das forças produtivas e do Estado. Essas categorias permitem compreender mais minuciosamente a forma como o capitalismo latino-americano se atrela ao capitalismo mundial e, assim, avançar na compreensão do subdesenvolvimento, tanto em sua teoria quanto em projetos que possibilitem sua superação.

Também em finais dos anos 1960 surgem os primeiros estudos sobre o "urbano" propriamente dito, que nascem de um esforço teórico no sentido de criticar a ecologia urbana da Escola de Chicago, cujo paradigma de interpretação sobre a definição do urbano era, então, o dominante (GOTTDIENER, 1997). Influenciados por Henri Lefèbvre, Manuel Castells e David Harvey, pelos cepalinos e dependentistas latino-americanos, surgem as primeiras interpretaçôes estruturalistas sobre o urbano na América Latina (ARANTES, 2009). Nessas interpretaçóes, como a de Luiz Pereira, Martha Schteingart e Paul Singer, pensa-se a urbanização como um processo específico, produto de uma industrialização ou, mais amplamente, de um capitalismo específicos. A cidade subdesenvolvida, periférica ou dependente tem sua expressão própria porque também é produto da reprodução das contradiçôes inerentes ao processo de subdesenvolvimento, que transporta para um outro nível as heterogeneidades estruturais, tanto econômicas quanto sociais, e, agora, mais do que nunca, espaciais.

A seguir trataremos das teorias produzidas sobre a urbanização latino-americana, que nasceram desses novos instrumentais para a compreensão do urbano. Não faremos a exposição por autores, mas sim pelos aspectos trazidos por eles para o debate sobre o processo de urbanização, particularmente sobre a importância da dimensão histórica na compreensão da dimensão urbana latino-americana. A essa dimensão histórica, atrelam-se outros temas importantes, necessários para a compreensão da especificidade da formação urbana no capitalismo latino-americano. $\mathrm{O}$ primeiro dos temas necessariamente atrelado à compreensão da especificidade da urbanização latino-americana refere-se à relação entre o rural e o urbano, atentando para o fato de que a reprodução de uma estrutura agrária desigual tem profundos impactos sobre o processo de urbanizaçáo; o segundo aspecto que aponta para a especificidade da cidade latino-americana é a relação entre esta e o processo de industrialização, entendido como o processo de constituição de forças produtivas em um capitalismo periférico específico; o terceiro tema que reforça a ideia de que a teoria do desenvolvimento deve não somente envolver a análise histórica mas também a multidisciplinaridade é a relação entre o Estado latino-americano que, devido ao seu caráter muitas vezes autoritário, restringe o direito à cidade na América Latina a alguns poucos.

\section{DESENVOLVIMENTO E URBANIZAÇÃO}

O retorno à História, ainda que esta tenha, por vezes, um viés evolucionista, é um aspecto comum a algumas abordagens sobre a urbanização latino-americana. O recurso à História, análise do passado, em consonância com a Economia Política do desenvolvimento, compreensão do presente, decorreu do questionamento a respeito da especificidade da urbanização latino-americana. Isso é comum a muitos 
dos autores aqui estudados, como Paul Singer, Fernando Henrique Cardoso, Aníbal Quijano, Martha Schteingart e Luiz Pereira.

Aníbal Quijano, sociólogo formado pela Universidade Nacional de Lima, no Peru, atenta para a relação entre urbanização, desenvolvimento e história no seguinte trecho de um artigo escrito para a Revista Mexicana de Sociologia, em 1968.

As sociedades nacionais latino-americanas - com exceção recente de Cuba - pertencem, individualmente e em conjunto, ao sistema de relaçóes de interdependência formado pelos países capitalistas e ocupam, dentro dele, uma situação de dependência. Do ponto de vista das nossas sociedades, trata-se antes de mais nada de um sistema de relaçóes de dependência. [...] Em consequência, não é possível explicar adequadamente o processo conjunto de mudança na América Latina, nem nenhuma das suas dimensões significativas, à margem dessa situação histórica. $\mathrm{O}$ processo de urbanização, em particular, só pode ser validamente explicado como parte da problemática mais ampla da sociologia da dependência latino-americana. (QUIJANO, 1978, p. 12-13)

Para ele, assim como para os demais teóricos da urbanização dependente, não é possível explicar o processo na América Latina, senão pelo entendimento de sua condição historicamente subordinada, que nasce da herança colonial e amadurece com a nação capitalista sob os laços de dependência externa.

A convivência entre estruturas arcaicas, herdadas do passado, e modernas, oriundas da difusão tecnológica de países mais adiantados para países mais atrasados, caracteriza náo somente o subdesenvolvimento como processo e estrutura senáo a própria urbanização periférica. O processo de modernização que vem com a industrialização substitutiva não é capaz de levar a economia periférica à condição do desenvolvimento.

Da mesma forma como a teoria do desenvolvimento cepalina pregava a necessidade da compreensão das raízes histórico-estruturais do sistema centro-periferia, voltando, para isso, ao período colonial, as intrepretaçóes sobre a urbanização dependente sempre partem da compreensão da cidade nesse mesmo contexto.

Não há, no entanto, paralelismo óbvio entre a compreensão da função de cidade no capitalismo dependente e sua relaçáo com a cidade no período colonial. Na realidade, esta é uma das críticas que fazemos aos autores que traçam essa relação imediata, como fazem Paul Singer e Fernando Henrique Cardoso, em seus textos publicados em 1972 pelo Cadernos Cebrap:

A cidade, que sedia o poder como uma de suas principais razóes de ser, domina politicamente o campo, impondo-lhe sua autoridade e sua lei. Nestes casos, a cidade sede do poder recebe um fluxo de recursos do campo, geralmente sob a forma de tributos, parte dos quais, pelo menos, é retida nela e serve ao sustento de uma parcela da população urbana [...].

$\mathrm{Na}$ medida, portanto, que a economia urbana exclui o contato direto com a natureza, a cidade não pode ser economicamente auto-suficiente e, de fato, quase nunca o é. $\mathrm{O}$ campo, pelo contrário, inclui entre as atividades que nele se realizam, as primárias, o que lhe permite, em princípio, ser economicamente autossuficiente. Desta maneira, a cidade praticamente sempre depende do campo para sua subsistência, enquanto o campo s6 depende da cidade a partir de um certo grau de especializaçáo das atividades que nele se desenvolvem. (SINGER, 1972, p. 3). 
O trecho acima, retirado do artigo de Singer, Campo e cidade no contexto histórico latino-americano, mostra a posição dos autores no que se refere à dominação política do campo pela cidade em todos os momentos da história. Para esses autores, essa dominação já está presente, já de forma embrionária, no período colonial. Aí, a cidade tem a função de intermediação entre a metrópole e a colônia, servindo para garantir a exploração do campo, que produz, dentro do antigo sistema colonial, o que é mais lucrativo à economia metropolitana. A função da cidade é, portanto, essencialmente política, como assim o será no capitalismo dependente: a de exercer o domínio sobre o campo.

Enquadramentos desse tipo, que generalizam para todos os períodos da história e para todos os lugares as relações entre as partes de um sistema, não dizem a partir de quando se considera a diferenciação entre cidade e campo, lembrando que, no capitalismo, a divisão do trabalho que se estabelece entre uma e outra é diferente. Embora a divisão exista em vários períodos da história, a partir do capitalismo a relação muda porque muda a natureza e a forma como se extrai o excedente. A indagação, indo mais além, perguntar-se-ia sobre natureza da relação entre campo e cidade na colônia, que, lembremos Caio Prado Júnior e Fernando Novais, não existe senão como prolongamento da metrópole ou como um dos pilares do capitalismo mercantil (PRADO Jr., 1994; NOVAIS, 2001).

Para Singer e Cardoso, enquanto na colônia a cidade é a expressão da dominação metropolitana, a partir da qual se extrai o espólio, em um país independente a cidade comanda a apropriação do excedente que será conservado dentro do território nacional. $\mathrm{O}$ excedente será destinado à reprodução da força de trabalho que se encontra na cidade industrial.

A cidade dependente, nascida do processo de consolidação do capitalismo na América Latina, exerce, em sua essência, a mesma função política que a do período colonial: a de domínio sobre o campo. Mesmo independentes politicamente, as cidades e as classes dominantes urbanas de um país de passado colonial inserem-se de maneira subordinada na divisão internacional do trabalho que configura o capitalismo mundial (CARDOSO, 1972).

Aqui cabe uma reflexão sobre as interpretações de Paul Singer e Fernando Henrique Cardoso a respeito da passagem da cidade colonial para a cidade na nação independente. Para evitar o anacronismo da análise de alguns processos, como o de urbanização, em naçôes de passado colonial, é necessário pensar, como Caio Prado Jr., que a colônia não estava fadada a ser naçáo. Dessa forma, seria mais adequado pensar o processo de urbanização, a produção espacial da cidade e da rede urbana, como resultante de um capitalismo específico, que traz marcado em suas estruturas o seu passado colonial. É na passagem da colônia para a naçáo capitalista que se redefinem as relaçóes entre cidade e campo, na forma da relação entre rural e urbano.

A cidade capitalista nasce com as Revoluçóes Industriais nos países centrais, mais propriamente com a II Revoluçáo Industrial em finais do XIX. Aí se completa a migração campo-cidade e a mão de obra, ao contrário das economias capitalistas subdesenvolvidas, tornava-se um fator escasso (FURTADO, 2000).

Para Marx e Engels ${ }^{4}$, a cidade é o lócus da concentração da força de trabalho, cuja exploração permitirá o movimento ininterrupto da acumulação do capital. Se, no campo, ainda havia a possibilidade de o trabalhador produzir para a própria subsistência, na cidade completa-se a separação entre o trabalhador e os meios de produção;
4 Sobre as condições em que vivia a classe trabalhadora na Inglaterra vide Friedrich Engels, A situação da classe trabalhadora na Inglaterra, publicado originalmente em 1844. 
completa-se, portanto, a dominação real do trabalho ao capital. É na cidade que a lei geral da acumulação capitalista, que expressa a produção paradoxal de miséria e riqueza no capitalismo, encontra sua forma mais crua (MARX, 2008b).

Se, por um lado, o processo de urbanização representa a força da industrializaçáo, por outro lado, expressa a dominaçáo plena do trabalho pelo capital. É somente na cidade que a superpopulação relativa, ou o exército industrial de reserva, pode existir. O urbano é, portanto, urbano não somente porque é industrial mas, sim, porque é o espaço em que se completa o conflito entre o capital e o trabalho. Por esse motivo, a produçáo da própria cidade é um elemento essencial no processo de acumulação de capital. Por isso também a permanente necessidade que as classes têm, na cidade, em buscar meios de segregação social, como o consumo, por exemplo. Algumas expressôes políticas, ou mesmo culturais, dos conflitos das classes capitalistas somente encontraram sua forma na cidade capitalista.

Para apreender o urbano em todas as suas dimensóes, seria interessante, ao invés de estabelecer uma conexão direta entre a cidade colonial e a cidade do capitalismo dependente, analisar a constituição do capitalismo periférico em diferentes momentos. A cidade periférica é o produto das condiçôes históricas da formação do capitalismo nos países que compóem a periferia do sistema.

O capitalismo periférico nasce com a primeira revolução industrial e consolida-se com a segunda, que inaugura a fase do capitalismo monopolista. Deve-se analisar, no entanto, os elementos particulares que conformaram o capitalismo periférico e, dentro deste, o latino-americano. São duas as passagens: a da colônia, que emerge da fase de acumulação primitiva, para a nação capitalista, que emerge no contexto do capitalismo concorrencial e se consolida ao longo do capitalismo monopolista. A segunda passagem, referente às relaçóes de produção, deve tratar de como se forma a força de trabalho livre sobre a escravidáo colonial.

Pensando em termos das diferentes transiçóes nacionais para o capitalismo, e a urbanização dentro desse processo, ressaltamos o esforço feito pela teoria do desenvolvimento e, particularmente, pela teoria marxista do desenvolvimento, para a compreensão da cidade latino-americana, partindo da transição da colônia para a nação capitalista. Nesse processo, não é possível pensar a cidade moderna como sinônimo da cidade industrial, nem no processo de industrialização na forma como se deu nos países centrais, tanto na Inglaterra quanto nos países do continente. Tampouco é possível generalizar a transição para a mão de obra livre, já que as naçóes latino-americanas eram, repetimos, originariamente escravistas.

Levando em consideração tais especificidades, parece-nos mais interessante pensar a forma como se deu a relação entre campo e cidade ao longo da passagem da condição colonial, um prolongamento da metrópole, para a nação capitalista. A relaçấo entre cidade e campo, como apontaremos a seguir, é um dos percursos necessários para explicar a especificidade histórica da urbanizaçáo latino-americana, dado o caráter concentrador da estrutura agrária que tem reflexos diretos sobre a estrutura de terra urbana e indiretos sobre a concentração de renda e a estruturação das classes sociais. Como colônia, a região que corresponderia à América Latina não tinha história própria, sendo determinada pela história do Império de que faziam parte. Dentro do sistema colonial, as cidades tanto tinham uma função na relação com a metrópole, a de lócus de dominação política, como também tinham uma função dentro da sociedade colonial. 
$\mathrm{Na}$ realidade, aí residem os elementos que explicam tanto as semelhanças quanto as diferenças assumidas pelas naçóes independentes. Como a sociedade colonial - esteja claro que estamos falando das colônias de exploração (PRADO Jr., 1994) - se originou da necessidade de complementar a metrópole, fornecendo-lhe produtos de base agrícola ou ouro, é no campo e nas minas onde primeiro se definem as estruturas de poder coloniais. Sendo assim, a cidade colonial não é simplesmente uma imposição do poder metropolitano mas também um lugar de embates entre o poder metropolitano e o colonial. Daí a natureza urbana dos movimentos nativistas e independentistas.

As classes dominantes na colônia podiam estar ligadas à burguesia mercantil metropolitana ou, no caso do Brasil, conformar uma classe que, em razáo da amplitude do território, podia ter uma relativa autonomia em relação à dominação exercida pela metrópole. Nesse caso, a cidade, lugar dos homens bons, era um prolongamento do campo e náo o seu contrário. Esse é o sentido do antiurbanismo colonial de Oliveira Vianna:

Este absenteísmo urbano, aliás, estava na lógica na nossa formação social. Muito ao contrário, tudo, na nossa sociedade colonial, nos educava e nos impelia para este antiurbanismo, para este centrifugismo à aglomeraçáo comunal - no que nos revelávamos inteiramente contrários à tendência dos povos peninsulares e mediterrâneos, das regióes da vide e do trigo, donde nos vinha o elemento povoador principal, todos inclinados, em geral, à comunidade de aldeia e à vivência urbana ou semiurbana. (VIANNA, 1999, p. 131).

Dado o caráter eminentemente agrário dessa classe dominante colonial é que se explica, na formação dos capitalismos latino-americanos, a continuidade de relaçóes de produção arcaicas, ligadas à produção primária, convivendo em paralelo com as modernas, oriundas do processo de industrializaçâo. Durante a fase primário-exportadora, os grandes proprietários, ligados às antigas atividades coloniais, preservaram seu poder se apropriando do Estado e se atrelando aos empresários capitalistas dos países centrais.

Portanto, por trás da condição primário-exportadora dessas economias de finais do século XIX até a crise de 1929, está uma oligarquia que conseguiu, a partir de relaçôes privilegiadas com o exterior, aumentar a produtividade de suas atividades, absorvendo progresso técnico e voltando-as para a exportaçâo. Para os teóricos cepalinos, a heterogeneidade estrutural encontraria aí suas raízes. Raízes estas que não são somente econômicas mas também políticas e sociais:

Se observamos o desenvolvimento econômico de uma perspectiva ampliada, isto é, como um processo histórico que interessa e inclui todos os povos, constatamos que o progresso tecnológico desempenha nele o papel fundamental. É porque existe progresso tecnológico em certas áreas, que são os polos do desenvolvimento mundial, que a acumulação alcança os elevados níveis que conhecemos e que as alteraçóes no perfil da demanda abrem caminho a significativas elevaçóes de produtividade [...] o que caracteriza uma economia dependente, é que nela o progresso tecnológico é criado pelo desenvolvimento, ou melhor, por modificaçóes estruturais, que surgem inicialmente do lado da demanda, enquanto nas economias desenvolvidas o progresso tecnológico é, ele mesmo, a fonte do desenvolvimento. De uma perspectiva mais ampla, cabe reconhecer que o desenvolvimento de 
uma economia dependente é o reflexo do progresso tecnológico nos polos dinâmicos da economia mundial. (FURTADO, 1968, p. 21-22).

Durante o processo de substituiçáo de importaçóes, que começa nos anos 1930 na América Latina, a classe ligada ao comércio de exportação continuou tendo uma função econômica e política fundamental. Afinal, era a partir do setor primário exportador que se obtinham as divisas necessárias à continuidade do processo de industrializaçáo. Por isso os países latino-americanos não assistiram a revoluçóes burguesas, uma vez que houve, dentro do próprio Estado, acomodação entre os interesses das classes agrárias tradicionais e os interesses das classes modernas industriais.

Outro processo histórico que confere especificidade à urbanizaçáo latino-americana é tratado a partir da conexáo entre a industrialização e o processo de urbanização. Conforme dito anteriormente, a classe proprietária de terra ou ligada à produção primária, cuja origem deitava raízes no período colonial, perpetuou o exercício de sua hegemonia até o início do processo de substituição de importaçôes. Com isso, não foi possível a realização da reforma agrária, o que manteve em países continentais, como o Brasil, grandes propriedades monocultoras, com produção voltada à exportação. Isso também tem profundos impactos sobre o processo de industrialização periférica e sobre a estrutura ocupacional urbana.

Lembremos do caráter específico da industrialização latino-americana, estudado pelos teóricos cepalinos desde o nascimento da problemática do desenvolvimento, dos anos 1940 até os anos 70 .

Para alguns teóricos, como o sociólogo brasileiro Vilmar Faria, a relação entre industrialização e urbanização define os contornos de uma nova rede urbana, associada a uma divisão do trabalho cujo centro é a cidade industrial. Ao atentarmos para a especificidade da industrialização latino-americana, a industrialização de caráter substitutivo, compreendemos a relaçáo entre rural e urbano no capitalismo subdesenvolvido, assim como a especificidade da metrópole dependente.

Pensando a urbanização como um fenômeno capitalista e o capitalismo como um modo de produção em cuja base material se conjugam forças produtivas, ligadas à industrializaçáo, e relaçôes de produção (MARX, 2008a), a cidade não pode ser capitalista somente por ser industrial, nem a urbanização uma decorrência do processo de industrialização. Afinal, o urbano se foi tornando mais complexo à medida que surgiam novas formas de acumulação - financeira e imobiliária -, ao mesmo tempo que outras formas - comercial, usurária, industrial - se mantinham.

É a partir da combinaçáo entre formas de acumulaçáo arcaicas e modernas que Milton Santos discute o espaço dividido, tratando, sob inspiração da teoria da dependência e do estruturalismo francês, dos dois circuitos que compóem a economia metropolitana. A composição desses dois circuitos, um moderno e um atrasado, na metrópole periférica, vai mais além da compreensão do processo de urbanização como um produto da industrialização. O circuito moderno é produto da alta tecnologia e serviços de ponta, enquanto o circuito atrasado é produto das formas primitivas de acumulaçáo capitalista, contando com máo de obra informal, baixa produtividade e baixo emprego de tecnologia: "[...] a diferença fundamental entre as atividades do circuito inferior e as do circuito superior está baseada nas diferenças de tecnologia e de organização" (SANTOS, 1978, p. 33).

A história que existe por trás da ideia da combinação desigual no urbano, de 
Milton Santos, é a história do processo de consolidação do capitalismo subdesenvolvido. Dentro deste, é preciso diferenciar que a industrialização é específica e compóe somente uma das dimensões contidas na esfera material, a dimensão correspondente às forças produtivas. Segundo Sérgio Silva, uma das principais insuficiências da teoria do desenvolvimento dos anos 1950 foi entender capitalismo como sinônimo de industrialização (SILVA, 1986). A outra dimensão que Silva (1986) aponta, a mais significativa mesmo na definição de um modo de produção para Marx, seria a das classes sociais. A compreensão da natureza das classes sociais capitalistas, e de sua relação com um processo de constituição de forças produtivas específico, é importante para a compreensão não somente da própria industrialização como da relaçáo entre rural e urbano, assim como a própria estrutura social urbana.

Quando a mecanização se estende ao campo, o que ocorre ao longo dos anos 1970, os países latino-americanos assistem a um intenso processo de migraçáo campo-cidade, sem que a cidade tivesse, por sua vez, condiçóes de receber táo imenso contingente de imediato. A preservação da estrutura agrária, assim como da classe a ela ligada, impediu que o processo de industrializaçáo fixasse mão de obra no campo e nas regiōes mais pobres. Essa força de trabalho, geralmente não qualificada, participaria, nas grandes metrópoles latino-americanas, do circuito de baixa produtividade, em que predominam os serviços, principalmente os informais:

A existência de uma massa de pessoas com salários muito baixos ou vivendo de atividades ocasionais, ao lado de uma minoria com rendas muito elevadas, cria na sociedade urbana uma divisão entre aqueles que podem ter acesso de maneira permanente aos bens e serviços oferecidos e aqueles que, tendo as mesmas necessidades, náo têm condiçóes de satisfazê-las. Isso cria ao mesmo tempo diferenças quantitativas no consumo. Essas diferenças são a causa e o efeito da existência, ou seja, da criação ou da manutenção, nessas cidades, de dois circuitos de produção, distribuição e consumo dos bens e serviços. (SANTOS, 1978, p. 29).

Essa migração rápida, com a composição de imensas periferias urbanas e um inchaço no setor terciário, é muito mais característica do processo de urbanização desigual, também termo de Milton Santos, do que a industrialização em si. Isso se relaciona, necessariamente, com a manutenção da estrutura da terra e das atividades tradicionais, assim como as classes que a elas se ligam, que, quando combinadas a tecnologias de elevada produtividade, expulsam mão de obra que irá contribuir para baixar ainda mais os salários nas grandes metrópoles.

Se a estrutura fundiária se manteve não foi somente por ditames econômicos mas também políticos. Foi porque a classe proprietária de terra, que se voltou aos ganhos de lucros com produtos primários produzidos para a exportação, tinha poder dentro dessa sociedade e dentro do próprio Estado. Não à toa, as reformas de base, táo proclamadas nos inícios dos anos 1960 e, depois, reproclamadas com os movimentos sociais que fecharam a década, não aconteceram.

Portanto, assim como não se pode entender a urbanização somente pelo processo de industrialização, atentando para que este seja somente uma das dimensóes da composição das forças produtivas em um país subdesenvolvido, não se pode compreendê-la sem classes. Também não se pode compreendê-la sem entender a relação que o Estado trava com essas classes e com o próprio processo de urbanização: 
A modernização, fenômeno reflexo das transformaçóes dos países mais adiantados, pode provocar a urbanizaçấo, sem contudo criar uma industrialização imediata. [...] Toda comparação pura e simples entre industrialização e urbanização, feita com o propósito de definir este último fenômeno, envolve o risco de negligenciar a possibilidade de análise histórica de maior alcance. (SANTOS, 1982, p. 55).

Além da relação específica entre rural e urbano que se dá no capitalismo periférico, que é a expressão aparente de uma dada estruturação de classes e de formas de acumulaçấo, temos de pensar sobre a maneira como se estruturaram as classes urbanas.

Nesse sentido, as décadas de 1960 e 70 são um campo riquíssimo, pois correspondem ao momento em que o processo de industrialização se consolida, sem que os países latino-americanos tenham superado sua condição subdesenvolvida. A compreensão de que desenvolvimento não consiste somente na industrialização avança, nos anos 1960, para a compreensão do desenvolvimento como destruição também de estruturas de poder, presentes no Estado, que impedem o avanço das reformas, principalmente agrária.

Nos anos 1970, a teoria do subdesenvolvimento, que pensa o capitalismo periférico como um tipo de capitalismo peculiar, em que as heterogeneidades se reproduzem à medida que contradiçóes específicas se acirram, passa a pensar o capitalismo latino-americano em termos de "estilos de crescimento".

A expressão aparece, pela primeira vez, em um texto de Aníbal Pinto, sociólogo chileno, um dos principais expoentes do pensamento cepalino. A ideia é a de mostrar que o processo de substituição de importaçôes se conduzira de tal maneira que, ao invés de seguir o que parecia ser o caminho inicial, partindo dos manufaturados mais simples aos mais complexos, embrenhara pela senda da substituição dos bens de consumo duráveis. Para Aníbal Pinto, este projeto se tornou viável, em primeiro lugar, por conta da alta liquidez internacional que facilitou o endividamento dos países latino-americanos. Em segundo lugar, devido ao processo de concentraçáo de renda, tanto em razão da alta inflação quanto em razão de políticas fiscais conduzidas deliberadamente pelos Estados ditatoriais da América Latina, como o arrocho salarial, por exemplo (PINTO, 2000).

Os anos 1970 são o momento de consolidação das grandes metrópoles latino-americanas, que criam novas heterogeneidades, ao mesmo tempo que reproduzem as heterogeneidades herdadas. Um dos meios principais pelos quais as heterogeneidades estruturais são reproduzidas é o Estado latino-americano, em sua feição autoritária e patrimonialista. Para Florestan Fernandes (2001), a consolidação do capitalismo dependente somente se pode fazer quando uma burguesia autocrática se apropria do Estado, excluindo a maior parte da população das benesses da modernizaçáo.

Com a produção e o consumo de bens duráveis, fenômeno tipicamente urbano, associado ao processo de concentração de renda, cria-se uma estrutura de classes na metrópole latino-americana que expressa também as contradiçôes de sua condição subdesenvolvida. Já vimos que o intenso movimento migratório, tanto do campo para a cidade como entre as regióes, criou uma estrutura ocupacional específica, basicamente assentada nos serviços urbanos nascidos na metrópole periférica. O estilo de desenvolvimento assentado no consumo de bens duráveis e na concentração de renda reforçou a desigualdade presente na estrutura de classes urbanas. 
Ao contrário dos países desenvolvidos, em que as estruturas sociais são convergentes, com as classes médias não se distanciando muito das classes mais altas nem das baixas, nos países subdesenvolvidos há distâncias colossais entre os estratos sociais. Isso se deu porque o estilo de crescimento com base nos bens duráveis exigiu que a concentração de renda e os créditos ao consumo se voltassem para as classes médias e altas. Os investimentos em indústrias de bens de consumo passaram a ser mais interessantes do que os investimentos em indústrias de base e bens de produção. A tấo famigerada estagnação, que Celso Furtado previa em meados dos anos 1960, e que decorreria da concentração de renda, não aconteceu. Ao contrário. Os anos 1970 mostraram, e isso reconhecem o próprio Celso Furtado (1974), em seu Mito do Desenvolvimento Econômico, Aníbal Pinto e Oswaldo Sunkel, que é possível crescimento com concentraçáo de renda. $\mathrm{O}$ crescimento passou a se alimentar, nos países subdesenvolvidos, das próprias heterogeneidades estruturais.

Além da acentuação das heterogeneidades sociais, que, em meio urbano, são ainda mais evidentes, Aníbal Pinto também chama a atenção para as heterogeneidades regionais, que tendem a reproduzir, dentro de um mesmo país, a lógica da relação centro-periferia. Isso se dá porque um centro regional tende a concentrar o processo de acumulaçáo que ocorre em níveis cada vez mais complexos - investimentos industriais, financeiros, comerciais -, assim como a mão de obra especializada, enquanto as demais regióes servem de periferia a essa acumulação, inclusive suprindo o polo central de matérias-primas e fornecendo força de trabalho barata.

Uma outra expressão dessa heterogeneidade regional é a divisão, dentro da própria metrópole, em centro e periferia, hoje, vários centros e várias periferias. A forma como se consolidou a sociedade de consumo, que é essencialmente urbana, no mundo periférico, também expressa a forma como se dá a segregação espacial urbana. Os meios de transporte públicos, diferentemente dos centros capitalistas, não se destinam originariamente à circulação rápida de força de trabalho, mas, por serem escassos, tornam o espaço por eles servidos cada vez mais caro e, paradoxalmente, cada vez mais restrito às classes mais elevadas. Isso, particularmente, no que se refere ao lazer e à habitação.

No caso brasileiro, a relação entre o crescimento da metrópole e a formação de uma sociedade de consumo que se assenta sobre bens originariamente de massa no capitalismo central, mas restritos a determinadas classes no capitalismo periférico, é clara. Segundo Regina Meyer (2010), São Paulo somente se pode consolidar como metrópole a partir do advento do automóvel e de sua produção em massa, com toda a infraestrutura que a produção desse bem durável trouxe consigo.

Os meios de transporte urbanos, assim como a habitação, expressam, no caso brasileiro, as contradiçôes do capitalismo subdesenvolvido e a ambiguidade de serem, paradoxalmente, mais próximos a bens de consumo, cujo acesso é garantido pela via do mercado, do que direitos sociais.

Isso nos leva a pensar, para a América Latina, como fica a questão do direito à cidade. Apesar de ser a ideologia que perpassa os Estatutos da Cidade, o direito à cidade, na periferia do sistema, não se fez sentir, em sua plenitude, no continente. Ao contrário dos direitos sociais conquistados a duras penas pelas classes trabalhadoras nas revoluçóes liberais de 1848, cuja luta continua ainda no pós II Guerra Mundial, os direitos sociais na América Latina não conseguiram ultrapassar a fronteira entre o bem de consumo e a cidadania. A modernização se faz, na América Latina, sem 
o direito à modernidade; e a urbanizaçáo, sem o direito à cidade. Como reforça Florestan Fernandes, a burguesia realiza o golpe de 1964, considerado uma revolução autocrática, para si mesma. A exclusão dos principais direitos, a democracia, a organização sindical, a saúde, a educação e a própria cidade, faz parte do caráter autocrático da Revolução Burguesa na América Latina, segundo Florestan Fernandes.

Chegar à questáo da cidadania nas sociedades capitalistas periféricas, relacionando-a com o processo de urbanização e com a constituiçáo do capitalismo periférico, conclui o artigo, cujo objetivo principal era o de sublinhar a atualidade da teoria da dependência, particularmente sua aplicação na compreensão do processo de urbanizaçáo latino-americano. Uma vez pensada como Economia Política, a teoria da dependência latino-americana pretendeu o resgate do passado, a compreensão do presente, não perdendo de vista um projeto para o futuro, que seria a superação das heterogeneidades que caracterizam o subdesenvolvimento. Há que se ter em vista que, hoje, a cidade latino-americana padece de males que somente podem ser explicados histórica e estruturalmente. Resgatar a questão urbana como questão social, livre dos determinismos de mercado que hoje a contaminam por meio da especulação imobiliária, significa o exercício pleno da teoria do desenvolvimento como Economia Política nessas três dimensôes: passado, presente e futuro.

\section{CONCLUSÃO}

Este artigo começou, inicialmente, a partir de uma proposta de se pensar os enfoques da teoria da dependência sobre a urbanização latino-americana. Percebeu-se, no entanto, que qualificar uma teoria de dependentista é algo um tanto reducionista. Os assim taxados dependentistas têm outras ideias para além da ideia de dependência e, dentro destes, inclui-se uma gama muito diversificada de autores, que vai de Ruy Mauro Marini a Florestan Fernandes, passando por Fernando Henrique Cardoso e Celso Furtado.

O que pensamos, então, foi dar um peso maior ao fato de os estudos sobre a urbanização, incluindo os que se consideram dentro da teoria da dependência, reforçarem a compreensão da economia do desenvolvimento como algo mais amplo, que deve necessariamente incluir o diálogo entre a teoria econômica e as

Milena Fernandes Oliveira é economista, mestre em História Econômica e doutora em Economia Aplicada/História Econômica pela Universidade Estadual de Campinas (UNICAMP); professora do Instituto de Economia (IE) da UNICAMP, Brasil.

E-mail: milena.foliveira@ gmail.com

Artigo recebido em setembro de 2014 e aprovado para publicação em novembro de 2014. demais ciências sociais. Nesse sentido, a análise do processo de urbanizaçáo em alguns autores que ficaram consagrados pelo tratamento da temática, como Luiz Pereira, Paul Singer e Martha Schteingart, envolve, necessariamente, um diálogo com a História, com a Ciência Política e com a Sociologia. A análise da economia do desenvolvimento mostrou-se insuficiente para captar as contradiçóes da constituição da dimensão urbana periférica. A teoria marxista foi, neste artigo, a mais enfatizada, não somente por uma afinidade da autora com esta mas por conta de sua facilidade em se transformar em movimento histórico, conferindo dinâmica e conteúdo social às estruturas. 


\section{BIBLIOGRAFIA}

ARANTES, P. Em busca do urbano: marxistas e a cidade de São Paulo nos anos 70. Novos Estudos CEBRAP, n. 83, p. 103-127, mar. 2009.

CARDOSO, F. H. A cidade e a política. In: ; SINGER, P. A cidade e o campo. São Paulo: Brasiliense, 1972. p. 29-61.

ENGELS, F. A situação da classe trabalhadora na Inglaterra. (1844) Trad. Rosa Camargo Artigas e Reginaldo Forti. São Paulo: Global, 1985.

FERNANDES, F. A Revolução Burguesa no Brasil-ensaio de interpretação sociológica. 5. ed. São Paulo: Globo, 2001.

FIORI, J. L. De volta à riqueza de algumas naçóes. Introdução. In: . Estados e moedas no desenvolvimento das naçóes. Petrópolis: Vozes, 2004. p. 11-48.

FONTANA, J. História: análise do passado e projeto social. 2· ed. Bauru: Edusc, 2004.

FRANK, A. G. Desenvolvimento do subdesenvolvimento latino-americano. In: PEREIRA, L. (Org.). Urbanização e Subdesenvolvimento. 4. ed. Rio de Janeiro, Zahar, 1979. p. 25-38

FURTADO, C. Um projeto para o Brasil. Rio de Janeiro: Saga, 1968. O mito do desenvolvimento econômico. Rio de Janeiro: Paz e Terra, 1974.

Desenvolvimento e Subdesenvolvimento. In: BIELSCHOWSKY, R. (Org.). Cinquenta anos de pensamento na Cepal. São Paulo; Rio de Janeiro: Record, 2000. p. 239-262.

GALÍCIA, S. R. Urbanização, mudança social e dependência. In: ALMEIDA, F. L. (Org.). A questão Urbana na América Latina. Rio de Janeiro: Forense - Universitária, 1978. p. 189-206

GOTTDIENER, M. A produção social do espaço urbano. São Paulo: EDUSP, 1997.

MARX, K. Contribuição à crítica da economia política. São Paulo, Expressão Popular, 2008a. O capital: crítica da economia política. 25. ed. Rio de Janeiro: Civilização Brasileira, 2008b.

MEYER, R. P. O carro e a evolução urbana e econômica de São Paulo. In: CARUSO, R. C. (Org.). O automóvel: o planejamento urbano e a crise das cidades. Florianópolis: Officio, 2010. p. 133-142.

NOVAIS, F. A. Portugal e Brasil na crise do antigo sistema colonial: (1777-1808). 7. ed. São Paulo: Hucitec, 2001.

OLIVEIRA, C. A. B. O processo de industrialização: do capitalismo originário ao atrasado. São Paulo: Ed. UNESP, 2003.

OLIVEIRA, O.; ROBERTS, B. O crescimento urbano e a estrutura urbana na América Latina. In: BETHELL, L. (Org.). História da América Latina: a América Latina após 1930: economia e sociedade. São Paulo: Edusp; Brasília: Fundação Alexandre de Gusmão, 2005. p. 299-384.

PEREIRA, L. Urbanização sociopática e tensões sociais na América Latina. In: ALMEIDA, F. L. (Org.). A questão Urbana na América Latina. Rio de Janeiro: Forense - Universitária, 1978. p. 61-124.

- Urbanização e subdesenvolvimento. In: Urbanização e Subdesenvolvimento. 4. ed. Rio de Janeiro: Zahar, 1979. p. 59-80.

PINTO, A. Natureza e implicaçôes da "heterogeneidade estrutural" na América Latina. In: BIELSCHOWSKY, R (Org.). Cinquenta anos de pensamento na Cepal. São Paulo; Rio de Janeiro: Record, 2000. p. 567-588.

PRADO Jr., C. Formação do Brasil contemporâneo. 23. ed.. São Paulo: Brasiliense, 1994. 
QUIJANO, A. Dependência, mudança social e urbanização na América Latina. In: ALMEIDA, F. L. (Org.). A questão Urbana na América Latina. Rio de Janeiro: Forense - Universitária, 1978. p. 9-60.

ROSANVALLON, P. O liberalismo econômico: história da ideia de mercado. Bauru: EDUSC, 2002.

SANTOS, M. O espaço dividido. Rio de Janeiro: Francisco Alves, 1978.

A urbanização desigual - a especificidade do fenômeno urbano em países subdesenvolvidos. 2. ed. Petrópolis: Vozes, 1982.

SCHTEINGART, M. Processos sociais e estruturação metropolitana na América Latina. In: ALMEIDA, F. L. (Org.). A questão Urbana na América Latina. Rio de Janeiro: Forense - Universitária, 1978. p. 125-164.

SILVA, S. Expansão cafeeira e origens da industrialização no Brasil. 7. ed. São Paulo: Alfa-Omega, 1986.

SINGER, P. Campo e cidade no contexto histórico latino-americano. In: CARDOSO, F. H. A cidade e o campo. São Paulo: Brasiliense, 1972. p. 3-27.

Urbanización, dependencia y marginalidad em América Latina. In SCHTEINGART, M. Urbanizacion y dependencia en America Latina. Buenos Aires: S.I.A.P., 1973. p. 93-122.

TAVARES, M. C. A retomada da hegemonia norte-americana. In: FIORI, J. L. Poder e dinheiro. Petrópolis: Vozes, 1997. p. 27-54.

VIANNA, O. Instituiçôes políticas brasileiras. Brasília: Conselho Editorial do Senado Federal, 1999.

A B S T R A C T : In the 1960s and 1970s, the theory of development Latin American has gone through a process of diversification and sophistication that made the economy closer to the social sciences. The theory was no longer centered in the treatment purely economic of the problem of economic development, such as the deterioration of the terms of the exchange, the generation of surplus and investment, but in the problems covering a treatment that regarded the social totality. In this sense, the interdisciplinary nature of the topics dealt with, including the classic theme of industrialization, began to be valued. At the same time that the theory of development becomes closer to a political economy of development, the themes help to consolidate this sophistication, showing the other facets of the underdevelopment and dependence. The need to explain the roots of underdevelopment has led to the study of the History and also the approach of social relations as relations of classes. A critical look at the role of the State has led to a widespread use of political science and of the structures of power. A study on the culture of consumption required the contribution of economic anthropology in this reconstruction of the discipline, new issues were covered, such as the peripheral urbanization, the structure of consumption, the agrarian structure, the regional heterogeneity. This work aims to understand how the study of urbanization in the periphery of the capitalist system, due to its specificity and complexity, has helped to strengthen this process of sophistication of the theory of economic development in Latin America, especially in his appeal to History and the other social sciences, like sociology and political science.

K E Y W O R D S : economic development; urbanization; theory of development; capitalism; Latin America. 